\title{
DISTÚRBIOS DO EQUILÍBRIO HIDROELETROLÍTICO
}

\author{
FLUID AND ELECTROLYTE DISORDERS
}

Osvaldo Merege Vieira Neto ${ }^{1} \&$ Miguel Moysés Neto²

\begin{abstract}
${ }^{1}$ Médico Assistente e Pós-graduando. ${ }^{2}$ Doutor em Nefrologia e Médico Assistente. Divisão de Nefrologia. Departamento de Clínica Medica. Faculdade de Medicina de Ribeirão Preto -USP.

Correspondência: Departamento de Clínica Médica. Faculdade de Medicina de Ribeirão Preto da Universidade de São Paulo - Campus Universitário - CEP: 14048-900 Ribeirão Preto - SP
\end{abstract}

VIEIRA NETO OM \& MOYSÉS NETOM. Distúrbios do equilíbrio hidroeletrolítico. Medicina, Ribeirão Preto 36: 325-337, abr./dez. 2003.

RESUMO - O sódio e o potássio são os principais íons dos meios extra e intracelular, respectivamente. Os distúrbios relacionados a esses íons são freqüentes e podem ser causados por inúmeras condições clínicas. A fisiopatologia e a gravidade das alterações indicam o tratamento a ser instituído. semia.

UNITERMOS - Sódio. Potássio. Hiponatremia. Hipernatremia. Hipopotassemia. Hiperpotas-

\section{1- DISTÚRBIOS DO EQUILÍBRIO DO SÓDIO}

O sódio é o íon mais importante do espaço extracelular, e a manutenção do volume do líquido extracelular depende do balanço de sódio. É mantido pelo organismo em níveis estreitos $(\mathrm{Na}=136$ a $145 \mathrm{mEq} / 1)$, sendo vários os mecanismos envolvidos no seu controle (osmorreceptores, barorreceptores, mecanismos extra-renais e sistema justaglomerular). Pode haver alterações no equilíbrio de sódio plasmático, aumentando ou diminuindo sua concentração, ocorrendo hipernatremia ou hiponatremia.

Existe uma estreita relação entre a água e o sódio, de tal modo que os distúrbios desses dois elementos não devem ser tratados de maneira independente.

\section{1- Hiponatremia}

\section{Definição}

A hiponatremia é definida como a concentração de sódio, no soro, inferior a $136 \mathrm{mEq} / 1$. É associada com diferentes doenças, e quase sempre é re- sultado de retenção hídrica. Na maioria das vezes, esse problema é devido à secreção inapropriada do Hormônio Anti diurético (HAD), embora a excreção de água livre possa estar limitada em algumas situações, como a insuficiência renal crônica, independente, e do HAD. Enquanto a hipernatremia sempre denota hipertonicidade, a hiponatremia pode estar associada a tonicidades baixa, normal ou aumentada. A osmolalidade efetiva ou tonicidade refere-se à contribuição da osmolalidade dos solutos, tais como sódio e glicose, que não podem se deslocar livremente através das membranas celulares, induzindo, portanto, deslocamentos transcelulares de água. A hiponatremia dilucional, a causa mais comum desse distúrbio, é provocada por retenção de água. Se a capacidade renal de excretar água é menor do que a ingestão, ocorre diluição dos solutos no organismo, provocando hiposmolalidade e hipotonicidade.

\section{Quadro clínico}

Na grande maioria das vezes, é assintomática, só ocorrendo sinais e sintomas nos casos graves. Ge- 
ralmente, até a concentração de $125 \mathrm{mEq} / \mathrm{l}$, não há sintomas. Eles são inespecíficos, e podem ocorrer em inúmeras condições clínicas. Os sintomas que podem ser vistos na hipo ou hipernatremia, são, primariamente, neurológicos e relacionados à gravidade e, particularmente, à rapidez na mudança da concentração plasmática de sódio (horas). A queda na osmolalidade plasmática cria um gradiente que favorece a entrada de água para dentro das células, levando ao edema cerebral. Vários sintomas e sinais podem estar relacionados à hiponatremia.

Sintomas: letargia, apatia, desorientação, cãimbras musculares, anorexia, náuseas e agitação.

Sinais: sensório anormal, reflexos profundos deprimidos, respiração de Cheyne Stokes, hipotermia, reflexos patológicos, paralisia pseudobulbar e convulsões.

\section{Classificação}

Pseudo-hiponatremia: a causa de hiponatremia é a elevada concentração de grandes moléculas de lípides (triglicérides e colesterol) e as paraproteinemias (mieloma múltiplo), que, ao deslocarem parte da água extracelular, reduzem, significantemente, a fração plasmática de sódio. A importância clínica da pseudo-hiponatremia e o seu tratamento são os mesmos da causa básica.

Hiponatremia hipertônica: é devida à presença, no soro, de solutos osmoticamente ativos, como manitol e glicose. É comum na cetoacidose diabética, na desobstrução do trato urinário, quando há diurese osmótica pela uréia, e em outras condições clínicas. $\mathrm{O}$ tratamento dessa condição é o mesmo da causa básica.

Hiponatremia hipotônica: na ausência de pseudo-hiponatremia ou da presença de outros solutos osmoticamente ativos, a hiponatremia evolui com hipotonicidade. É importante a avaliação do volume extracelular, pois, estando aumentado, normal ou diminuído, poderemos ter hiponatremia com sódio corporal total alto, normal ou baixo, respectivamente. Sendo assim, usaremos a classificação que vem a seguir:

1) Expansão do volume extracelular: resulta da diminuição da excreção renal de água, com conseqüente expansão da água corporal total, maior do que o sódio corporal total, e a diminuição do sódio sérico. Freqüentemente, esses pacientes são edematosos, o que ocorre nas seguintes situações clínicas: insuficiência cardíaca, cirrose hepática, síndrome nefrótica e insuficiência renal. Em tais condi- ções, o tratamento da hiponatremia consiste na correção do distúrbio subjacente e na restrição hídrica, freqüentemente em associação com diuréticos.

2) Volume extracelular normal: a hiponatremia, associada com euvolemia, inclui situações clínicas que descreveremos a seguir

a) Hipotiroidismo: a ocorrência de hiponatremia em hipotiroidismo, geralmente, sugere doença grave, incluindo coma mixedematoso. O tratamento consiste na reposição hormonal e na restrição hídrica.

b) Deficiência de corticosteróide: as deficiências de glicocorticóide e/ou mineralocorticóide podem levar à hiponatremia, devido as suas ações no metabolismo de sódio e da água. Deve-se pesquisálas, quando a causa de hiponatremia não é evidente, em pacientes euvolêmicos. $\mathrm{O}$ tratamento consiste na reposição hormonal e restrição hídrica.

c) Estresse emocional, dor e drogas: dor aguda ou estresse emocional grave, como na psicose, associada com ingestão contínua, podem levar a hiponatremia grave. Há drogas que estimulam a liberação do $\mathrm{HAD}$, provocando hiponatremia. $\mathrm{O}$ tratamento consiste na correção da causa básica ou suspensão da droga, se ela for a causa, associada à restrição hídrica. As drogas que estimulam a liberação de hormônio antidiurético ou que aumentam sua ação incluem: inibidores das prostaglandinas, nicotina, clorpropamida, tolbutamida, clofibrato, ciclofosfamida, morfina, barbitúricos, vincristina, carbamazepina (tegretol), acetaminoafen, fluoxetina e sertralina. Pacientes acima de 65 anos são mais susceptíveis.

d) Síndrome da secreção inapropriada do HAD (SIHAD): após a exclusão dos diagnósticos acima, em pacientes hiponatrêmicos, euvolêmicos, tal diagnóstico deve se considerado. A retenção de água e a expansão de volume, nessa síndrome, leva a um achado freqüente, que é oposto àquelas situações em que há hipovolemia: a hipouricemia (concentração plasmática de ácido úrico $<4 \mathrm{mg} / \mathrm{dl}$ ). As causas principais estão listadas a seguir.

- Carcinomas: pulmão, duodeno, pâncreas

- Distúrbios Pulmonares: pneumonia viral, pneumonia bacteriana, abscesso pulmonar, tuberculose, aspergilose

- Distúrbios do sistema nervoso central (SNC): encefalite viral ou bacteriana, meningite viral, bacte- 
riana ou tuberculosa, psicose aguda, acidente vascular cerebral (isquêmico ou hemorrágico), tumor cerebral, abscesso cerebral, hematoma ou hemorragia subdural ou subaracnóide, Síndrome de Guillain-Barré, traumatismo craniano, outras causas, como pós-operatórios, dor, náusea intensa e síndrome de imunodeficiência adquirida.

OBS: todas as alterações no balanço hidroeletrolítico, observadas na SIHAD, têm sido, também, observadas na suposta síndrome de perda de sal de origem cerebral. Essa síndrome é caracterizada por elevada concentração de sódio na urina, causada pela alteração na reabsorção de sódio tubular mediada pela liberação de um hormônio natriurético, talvez, um peptídeo originado no sistema nervoso central, com conseqüente hiponatremia e perda de volume. Os níveis séricos de ADH não são úteis na diferenciação entre as duas síndromes. Os níveis séricos de ácido úrico, geralmente, estão normais na síndrome de perda de sal, de origem cerebral. A hipovolemia, traduzida por hipotensão ou desidratação, seria a única manifestação clínica, que distinguiria essa síndrome da SIHAD. O tratamento é diferente para cada situação.

e) Ingestão diminuída de solutos: abuso de ingestão de cerveja ou de dietas com baixo teor de proteínas e excesso de ingestão de água, levando a diminuição do metabolismo protéico e baixa produção de uréia. A baixa excreção de solutos reduz a excreção máxima de água, embora a capacidade de diluição do rim possa estar preservada.

O tratamento da SIADH consiste na restrição hídrica e no uso eventual de diuréticos de alça, com reposição do sódio e do potássio perdidos na urina. Nos casos que não respondem à restrição hídrica, podese usar drogas que induzam diabetes insípido nefrogênico, como a demeclociclina (600-1200 mg/ dia) e Carbonato de Lítio. Foram desenvolvidos, também, antagonistas específicos do HAD, em animais, e que deverão estar disponíveis, no futuro, para uso clínico em pacientes.

3) Contração do volume extracelular: existem inúmeras condições clínicas em que a hiponatremia evolui com contração do volume extracelular, podendo ocorrer perda de sódio através da pele, trato gastrointestinal ou rim. A concentração de sódio urinário pode estar baixa $(<20 \mathrm{mEq} / \mathrm{l})$, devido à ávida reabsorção tubular de sódio pelo rim, nas perdas extra-renais. Porém, quando a concentração urinária de sódio estiver mais alta (> 20mEq/l), devese considerar que o rim não está respondendo apropriadamente e/ou que essas perdas, provavelmente, são as causas da hiponatremia. As causas mais freqüentes são as relatadas a seguir.

a) Perdas gastrointestinais ou para o terceiro espaço: nos pacientes com hipovolemia, hiponatremia e sódio urinário menor que $10 \mathrm{mEq} / 1$, devemos considerar perdas gastrointestinais. São mais facilmente diagnosticadas em pacientes com história de vômitos e/ou diarréia, porém, na ausência destes, devem ser consideradas: perdas para o terceiro espaço, como nos casos de peritonite e pancreatite, em que há perdas para a cavidade abdominal; íleo ou colite pseudomembranosa, em que há perdas para a luz intestinal; queimaduras, em que há perdas pela pele; e traumatismos musculares, em que há perdas para o músculo. Uso abusivo de catárticos deve ser investigado, mesmo sem história de perdas gastrointestinais. A terapêutica consiste na hidratação com solução salina isotônica.

b) Perdas renais: sódio urinário maior que $20 \mathrm{mEq} / 1$

- Uso de diuréticos: a queda da natremia, em pacientes recebendo diuréticos, pode ser o primeiro sinal indicador da necessidade de reajustar suas doses. Freqüentemente, a depleção de volume não é evidente ao exame clínico, e um dado importante é que os pacientes hiponatrêmicos, em uso de diuréticos tiazídicos ou de alça, apresentam alcalose metabólica ou hipocalêmica, o que não ocorre, quando são utilizados diuréticos poupadores de potássio. A melhor maneira de confirmar esse diagnóstico é a suspensão do uso do diurético.

- Uso abusivo de diuréticos: é comum em mulheres na pré-menopausa, que o fazem por razões estéticas e para perder peso, de maneira escondida. Evoluem com alcalose metabólica, hipocalêmica. O tratamento consiste na orientação quanto ao uso excessivo de diuréticos.

- Nefrite perdedora de sal: pacientes portadores de doença cística medular, nefrite intersticial crônica, doença renal policística, obstrução parcial do trato urinário e, raramente, glomerulonefrite crônica, podem apresentar hiponatremia hipovolêmica, o que acontece, geralmente, em pacientes com insuficiência renal moderada ou avançada, devido à perda da capacidade de concentração urinária. $\mathrm{O}$ tratamento consiste na hidratação com salina isotônica. 
- Doença de Addison: pacientes com tal patologia apresentam menores níveis de aldosterona e, conseqüentemente, reabsorvem menos sódio e excretam mais potássio pelos rins. As concentrações urinárias de sódio são maiores do que $20 \mathrm{mEq} / 1$ e as de potássio menores do que $20 \mathrm{mEq} / 1$, e podem ser uma pista para esse diagnóstico. A terapêutica consiste na reposição hormonal e hidratação com salina isotônica.

- Diurese osmótica e excreção de amônia: na presença de concentração de sódio urinário maior do que $20 \mathrm{mEq} / 1$, deve-se considerar, também, a diurese osmótica, levando à depleção de água e eletrólitos. Podem-se citar algumas situações em que isso ocorre eletrolítica.

- Infusão crônica de manitol, sem reposição

- Desobstrução do trato urinário, com diurese osmótica pela uréia.

- Diabetes não controlada, com glicosúria importante, causando diurese osmótica e conseqüente espoliação hidroeletrolítica.

- Cetonúria, em que a excreção de cetoácidos pode levar à perda renal de água e eletrólitos, como na cetoacidose diabética e alcoólica ou na inanição.

- Bicarbonatúria, em que a perda renal do bicarbonato leva à perda de água e cátions, para manter a eletroneutralidade. É mais freqüentemente encontrada na alcalose metabólica com bicarbonatúria, comum nos pós-operatórios com sucção nasogástrica ou vômitos. A acidose tubular renal proximal pode, também, levar a bicarbonatúria, com conseqüente hiponatremia.

4) Excesso de ingestão de água: existem algumas situações em que existe hiponatremia com supressão da excreção de HAD: insuficiência renal avançada e polidipsia primária. No primeiro caso, rim excreta água livre pela incapacidade do néfron em diluir a urina. A osmolalidade urinária pode se elevar para 200 a $250 \mathrm{mOs} / \mathrm{kg}$, pelo aumento da excreção de solutos por néfron. No caso da polidipsia primária ,o sódio plasmático pode estar normal ou discretamente rebaixado pelo excesso de ingestão de água, devido ao estímulo patológico da sede. Podem ocorrer por lesões hipotalâmicas como, sarcoidose, ou em pacientes com distúrbios psiquiátricos. Ingestões acidentais de água, durante aulas de natação, excesso de enemas ou soluções de irrigação, utilizadas em cirurgias de próstata transuretrais (RTU) podem, também, levar a quadro de hiponatremia hipotônica.

\section{Terapêutica}

As causas mais comuns de hiponatremia grave, em adultos, são a terapia com tiazídicos, pós-operatórios, SIHAD, polidipsia em pacientes psiquiátricos e prostatectomia por ressecção transuretral.

O tratamento pode variar desde restrição hídrica até reposição de salina isotônica ou hipertônica. Porém, em casos de hiponatremia sintomática, o que, geralmente, pode ocorrer com sódio entre $120 \mathrm{mEq} / 1$ e $125 \mathrm{mEq} / \mathrm{l}$, deve-se fazer a reposição salina, independente da causa, especialmente se a hiponatremia ocorreu de maneira muito rápida.

Embora rara, a desmielinização osmótica é séria e pode ocorrer de um a vários dias após o tratamento mais agressivo de hiponatremia por qualquer método, mesmo em resposta à restrição hídrica, como tratamento único. A contração das células cerebrais desencadeia a desmielinização dos neurônios da ponte e extrapontinos e causa disfunção neurológica, incluindo quadriplegia, paralisia pseudobulbar, convulsões, coma e até óbito. A desnutrição, hepatopatias e déficit de potássio aumentam o risco dessa complicação.

$\mathrm{O}$ aumento da concentração de sódio não deve exceder de 8 a $10 \mathrm{mEq} / \mathrm{l}$ nas $24 \mathrm{~h}$ até atingir os níveis entre $125 \mathrm{mEq} / \mathrm{l}$ a $130 \mathrm{mEq} / \mathrm{l}$. Se a concentração inicial estiver abaixo de $100 \mathrm{mEq} / \mathrm{l}$, por exemplo, a correção poderá aumentar sua velocidade para 1 a $2 \mathrm{mEq} / \mathrm{l}$ por hora até atingir níveis satisfatórios ou melhora da sintomatologia. A correção pode ser feita pela fórmula:

$$
\text { Mudança no sódio sérico }(\mathrm{mEq} / \mathrm{l})=\frac{\mathrm{Na} \text { infundido }-\mathrm{Na} \text { sérico }}{\text { Água corporal }+1}
$$

Água corporal $=$ calculada como fração do peso. $\mathrm{O}$ índice para adultos e crianças é 0,6 , para mulheres e idosos, 0,45 a 0,5 . A fórmula estima o efeito de um litro de qualquer solução infundida no sódio sérico

\section{- Hiponatremia hipotônica sintomática}

Pacientes que têm hiponatremia com urina concentrada, osmolalidade $>200 \mathrm{mOsm} / \mathrm{kg}$ de água, euvolêmicos ou hipervolêmicos necessitam de infusão de salina hipertônica. A solução hipertônica deve ser acompanhada de furosemide para evitar a expansão do volume extracelular. Como a diurese por furosemide equivale a solução salina a $0,45 \%(77 \mathrm{mEq} / \mathrm{l})$, ajuda na correção da hiponatremia, porém, deve-se 
Tabela I - Soluções que poderão ser utilizadas para reposição para hipo e hipernatremia

\begin{tabular}{l|c|c|}
\hline Solução a ser infundida & Quantidade $\mathbf{~} \mathbf{N}$ Na $(\mathbf{m E q} / \mathbf{l})$ & Distribuição p/líquido extracelular (\%) \\
\hline Salina a 5\% & 855 & $100 *$ \\
\hline Salina a 3\% & 513 & $100 *$ \\
\hline Salina a 0,9\% & 154 & 100 \\
\hline Solução de Ringer lactato & 130 & 97 \\
\hline Salina a 0,45\% & 77 & 73 \\
\hline Salina a 0,2\% em glicose a 5\% & 34 & 55 \\
\hline Glicose a 5\% & 0 & 40 \\
\hline * Além de distribuição total no compartimento extracelular, essas soluções induzem remoção por osmose de água do compartimento \\
intracelular
\end{tabular}

evitar a infusão de água livre de solutos ao mesmo tempo. Pacientes com urina diluída (osmolaridade < $200 \mathrm{mOsm} / \mathrm{kg}$ de água), sem sintomas graves, usualmente, só necessitam de restrição de água. Sintomas mais graves, como convulsão e coma, podem indicar a necessidade do uso de soluções hipertônicas.

\section{- Hiponatremia hipotônica assintomática}

O grande risco do tratamento, nesses casos, ocorre durante a fase de correção, quando os pacientes param de ingerir grandes quantidades de água ou quando há correção repentina da dificuldade de excreção de água, como aquelas provocadas por drogas. Se há uma diurese excessiva, em alguns casos, há necessidade da administração de líquidos hipotônicos, para evitar que a correção se processe acima da meta estipulada de $10 \mathrm{mEq} / \mathrm{l} / 24 \mathrm{~h}$, por exemplo. Por outro lado, não há risco semelhante associado com a hiponatremia assintomática, que acompanha os estados edematosos ou a persistência da SIHAD pela alteração na excreção de água. Na ICC grave, a mudança das condições hemodinâmicas pode melhorar a excreção de água livre. Nesses casos, o uso de furosemide e não o de tiazídico, reduz a concentração urinária e aumenta a excreção de água livre. $\mathrm{Na}$ SIHAD, deve-se utilizar diuréticos de alça, associados com solução salina hipertônica o que vai aumentar a perda de água. A administração de sódio, em solução hipertônica, não deve ser dada aos pacientes portadores de estados edematosos.

Embora a restrição de água vá melhorar todas as formas de hiponatremia, essa não é a melhor terapia em todos os casos. A hiponatremia associada com a perda de volume e líquido extracelular, como, por exemplo, nas diarréias e perdas gastrointestinais, necessita também de correção da perda de sódio concomitante.

A hiponatremia adquirida dentro do hospital pode ser prevenida, detectando-se situações que possam diminuir a excreção de água; drogas; insuficiência de órgãos, como insuficiência renal e cardíaca; pós-operatórios. Nesses casos, deve-se evitar a infusão de líquidos hipotônicos, que excedam a capacidade de excreção de água dos pacientes de risco.

\section{2- Hipernatremia}

\section{Definição}

A hipernatremia é definida, quando o sódio plasmático ultrapassa $145 \mathrm{mEq} / \mathrm{I}$. A concentração sérica de sódio e, consequientemente, a osmolalidade sérica são controladas pela homeostase da água, a qual é mediada pela sede, pela vasopressina e pelos rins. Qualquer desequilíbrio, no balanço de água, manifesta-se como uma anormalidade da concentração sérica de sódio: hipernatremia ou hiponatremia. É menos freqüente do que a hiponatremia, e mais comum em pacientes muito jovens, muito velhos, e doentes, que não têm condição de ingerir líquido em resposta ao aumento de osmolalidade, o que provoca sede, devido a sua incapacidade física. Como o sódio funciona como soluto impermeável, do ponto de vista funcional, ele contribui para a tonicidade, e induz o movimento de água através das membranas celulares. A hipernatremia, inva- 
riavelmente, evolui com hiperosmolalidade hipertônica e sempre provoca desidratação celular. A hipernatremia ocorre com frequiência em pacientes hospitalizados, como uma condição ligada a fatores iatrogênicos, e algumas das complicações mais sérias ocorrem não da própria alteração, mas de tratamento inadequado.

\section{Quadro clínico}

A hipernatremia pode ser sintomática e levar a sinais e sintomas clínicos.

Disfunção do SNC: É conseqüente à desidratação celular, com contração das células cerebrais, o que pode levar à laceração, hemorragia subaracnóide e subcortical, e trombose dos seios venosos. As primeiras manifestações da hipernatremia são: agitação, letargia e irritação. Esses sintomas podem ser seguidos de espasmos musculares, hiperreflexia, tremores, ataxia. A hipernatremia aguda é mais grave do que a crônica, e a evolução mais benigna, nos casos crônicos, deve-se à formação de osmóis ideogênicos, osmoticamente ativos para restauração de água intracelular. A gravidade dos sintomas cabíveis depende da idade, e é maior em pacientes muito jovens ou muito velhos.

\section{Classificação}

\section{Perda de água}

1) Perdas insensíveis: pela pele e pela respiração.

2) Diabetes insipidus: após trauma, provocado por tumores, cistos, histiocitose, tuberculose, sarcoidose, idiopático, provocado por aneurismas, meningite, encefalite, síndrome de Guillain-Barré, e transitório, provocado por ingestão de etanol.

\section{3) Diabetes insipidus nefrogênico}

- Doença renal (doença cística medular, por exemplo)

- Hipercalcemia ou hipocalemia.

- Drogas: lítio, demeclociclina, foscarnet, metoxiflurano, anfotericina B.

\section{Perda de líquidos hipotônicos}

1) Causas renais: diuréticos de alça, diurese osmótica (glicose, uréia, manitol), diurese pós desobstrução, fase diurética da necrose tubular aguda.

2) Causas gastrointestinais: vômitos, drenagem nasogástrica, fístulas enterocutâneas, diarréia, uso de agentes catárticos, como, por exemplo, a lactulose

3) Causas cutâneas: queimaduras, sudorese excessiva

\section{Ganho de sódio hipertônico}

Infusão de bicarbonato de sódio, ingestão de cloreto de sódio, ingestão da água do mar, enemas de salina hipertônica, infusão de soluções hipertônicas de sódio, diálise hipertônica, hiperaldosteronismo primário e síndrome de Cushing (reabsorção intensa de sódio pelos túbulos).

\section{Terapêutica}

O tratamento se inicia com o diagnóstico da causa do processo e corrigindo a hipertonicidade. $\mathrm{O}$ tratamento das causas pode, por exemplo, controlar a perda de líquidos gastrointestinais, controlar o aumento de temperatura, hiperglicemia, corrigir a poliúria pelo lítio, etc. Nos pacientes com hipernatremia, que se desenvolve após algumas horas, a correção rápida melhora o prognóstico, sem risco de provocar edema cerebral. Nesses pacientes, a redução de $1 \mathrm{mEqL} / \mathrm{l} / \mathrm{h}$ é adequada. Uma correção mais prudente torna-se necessária nos pacientes com hipernatremia de longa duração ou de duração desconhecida, devido ao fato que a dissipação do acúmulo dos solutos cerebrais pode levar vários dias. Nesses casos, deve-se reduzir a diminuição da concentração de sódio sérico a $0,5 \mathrm{mEq} /$ h o que evita o aparecimento de edema e convulsões. Recomenda-se que a queda do sódio plasmático não exceda a $10 \mathrm{mEq} / \mathrm{l}$ nas $24 \mathrm{~h}$. O objetivo do tratamento é levar os níveis do sódio sérico a $145 \mathrm{mEq} / \mathrm{l}$.

A fórmula a ser utilizada é a mesma utilizada para correção da hiponatremia, como visto anteriormente.

$$
\text { Mudança no sódio sérico }(\mathrm{mEq} / \mathrm{l})=\frac{\mathrm{Na} \text { infundido }-\mathrm{Na} \text { sérico }}{\text { Água corporal }+1}
$$

Água corporal $=$ calculada como fração do peso. $\mathrm{O}$ índice, para adultos e crianças, é 0,6 , para mulheres e idosos, 0,45 a 0,5 . A fórmula estima o efeito de um litro de qualquer solução infundida no sódio sérico

A via preferencial para correção, quando possível, é a oral através de sondas nasogástricas ou enterais. Se não for possível, administrar, por via endovenosa, soluções hipotônicas, como glicose a 5\%, salina a $0,2 \%$ (diluir o sódio em solução glicosada a $5 \%$ ) e salina a $0,45 \%$. Quanto mais hipotônico o líquido de infusão, mais lenta deve ser a administração. 
Tabela II - Soluções que poderão ser utilizadas para reposição para hipernatremia

Solução a ser infundida

Salina a $0,9 \%$

Solução de Ringer lactato

Salina a $0,45 \%$

Salina a $0,2 \%$ em glicose a $5 \%$

Glicose a $5 \%$
Quantidade de Na $\mathrm{mEq} / \mathrm{l})$

154

130

77

34

0
Distribuição p/líquido extracelular(\%)

100

97

73

55

40
A não ser em casos de comprometimento hemodinâmico, a solução salina a $0,9 \%$ não é adequada para o manuseio da hipernatremia. Como exemplo, um paciente que tem concentração de sódio de $162 \mathrm{mEq} /$ 1, pesando $70 \mathrm{~kg}$, ao receber um litro de salina a $0,9 \%$, diminuirá em somente $0,2 \mathrm{mEq} / \mathrm{l}$ a concentração sérica de sódio, não alterando substancialmente essa concentração. Além disso, se persistirem as perdas de líquidos hipotônicos, a natremia poderá aumentar ao invés de diminuir. A única indicação de salina a um paciente com hipernatremia é quando houver perda de volume extracelular suficiente para provocar alterações hemodinâmicas. Mesmo nesses casos, assim que as condições hemodinâmicas se estabilizarem, deve-se administrar soluções hipotônicas, como salina a $0,2 \%$ e $0,45 \%$, para corrigir a hipernatremia.

Nos casos em que há hipernatremia por ganho de soluções hipertônicas de sódio, a administração de furosemide somente agravará a hipernatremia, já que a diurese induzida equivale a, aproximadamente, solução salina a $0,45 \%$. A administração concomitante de diurético e solução com água livre será mais adequada. Há necessidade de monitoração contínua, pois há risco de retenção de volume extracelular nesses casos. A hipernatremia, na vigência de insuficiência renal e sobrecarga de volume, é um capítulo a parte, mas, geralmente, a diálise pode ser necessária.

\section{2- DISTÚRBIOS DO EQUILÍBRIO DO PO- TÁSSIO}

Dentre os distúrbios encontrados na prática clínica, os relacionados ao potássio são muito freqüentes e, muitas vezes, constituem-se em emergência clínica. Procuramos dar uma rápida noção da distribuição do potássio corporal, das possíveis etiologias dos distúrbios relacionados ao potássio e seu enfoque terapêutico.

\section{1- Distribuição do potássio}

O potássio é um íon predominantemente intracelular. O conteúdo corporal de potássio é de cerca de $50 \mathrm{mEq} / \mathrm{kg}$ ou seja, cerca de $3.500 \mathrm{mEq}$ para um adulto de aproximadamente $70 \mathrm{~kg}$. A concentração intracelular de potássio varia de 140 a $150 \mathrm{mEq} / 1$, sendo o tecido muscular o maior depósito de potássio. Apenas 2\% do potássio corporal total encontra-se no espaço extracelular, variando sua concentração de 3,5 a 5,0 mEq/1. Devido à grande diferença entre as concentrações intra e extracelular de potássio, os fatores que controlam sua distribuição transcelular são críticos para a manutenção de níveis séricos normais. Os principais fatores são:

A- pH: a acidose provoca a saída de potássio do intra para o extracelular, aumentando sua concentração sérica . Isto ocorre porque, quando excesso de íons $\mathrm{H}^{+}$são adicionados ao plasma, a maior parte é tamponada no compartimento intracelular, e, para que esses íons entrem para dentro das células, eles são trocados por íons $\mathrm{Na}^{+}$, através do trocador $\mathrm{Na}^{+}-\mathrm{H}^{+}$, o que diminui a concentração de $\mathrm{Na}^{+}$intracelular, e, conseqüentemente, sua disponibilidade para ser trocado pelo $\mathrm{K}+$ através da bomba $\mathrm{Na}^{+}-\mathrm{K}^{+}$ATPase. Dessa maneira, menor quantidade de $\mathrm{K}^{+}$entra nas células. $\mathrm{O}$ fenômeno oposto ocorre na alcalose. Alterações do bicarbonato sérico, mesmo sem alterações do $\mathrm{pH}$, levam a alterações da distribuição transcelular. De forma prática, para cada $0,1 \mathrm{U}$ de alteração do $\mathrm{pH}$ sanguíneo haverá uma alteração concomitante do potássio sérico de $0,6 \mathrm{mEq} / 1$.

B - Insulina: exerce um papel importante na manutenção da distribuição sérica normal,/ do potássio. Indivíduos com baixa secreção basal de insulina (ex: diabéticos do tipo 1 ) possuem menor tolerân- 
cia à infusão de potássio, por apresentarem mecanismos de defesa debilitados frente a situações de hiperpotassemia). A insulina exerce seu efeito protetor na hiperpotassemia através do aumento da captação de potássio pelas células hepáticas e musculares. Seu efeito ocorre através da estimulação do trocador $\mathrm{Na}^{+}-\mathrm{H}^{+}$, com entrada de $\mathrm{Na}^{+}$e saída de $\mathrm{H}^{+}$. Dessa maneira, ocorre um aumento da extrusão de $\mathrm{Na}$ intracelular através da bomba $\mathrm{Na}^{+}-\mathrm{K}^{+}$ATPase, com conseqüente entrada de $\mathrm{K}^{+}$ para dentro das células.

C-Aldosterona: o principal efeito da aldosterona ocorre através da modificação da excreção renal de potássio. Sua ação ocorre no ducto coletor, abrindo canais de $\mathrm{Na}^{+}, \mathrm{o}$ que aumenta a reabsorção desse cátion, com conseqüente secreção de $\mathrm{K}^{+}$. É provável que a aldosterona também atue, promovendo a captação celular de potássio, entretanto tal dado ainda não se encontra estabelecido no homem.

D- Agentes $\boldsymbol{\beta}_{\mathbf{2}}$-Adrenérgicos: atuam diretamente na bomba $\mathrm{Na}^{+}-\mathrm{K}^{+}$

ATPase estimulando-a, com conseqüente entrada de $\mathrm{K}^{+}$e saída de $\mathrm{Na}^{+}$. Esse efeito é mediado pelos receptores $\beta_{2}$-adrenérgicos e é mais evidente com o uso de adrenalina.

Além dos fatores mencionados, que controlam a distribuição transcelular do potássio, têm papel relevante as alterações da reserva corporal total, seja por depleção (aumento das perdas ou redução da ingesta) ou retenção de potássio (sobrecarga de potássio ou diminuição das perdas renais.

\subsection{Hiperpotassemia}

\section{Definição}

Concentração plasmática do íon potássio acima de $5,0 \mathrm{mEq} / 1$. Deve-se excluir a pseudo-hiperpotassemia, que ocorre nas seguintes situações:

- Leucocitose: acima de $100.000 / \mathrm{mm}^{3}$

- Plaquetose: acima de $1.000 .000 / \mathrm{mm}^{3}$

- Hemólise

\section{Etiologia} tassemia

$\mathrm{Na}$ Tabela III, as causas possíveis de hiperpo-

Acidose metabólica ou respiratória Insuficiência renal

Carga de potássio exógena

Carga de potássio endógena

-Esmagamento

-Hemólise

-Hipercatabolismo

Diuréticos poupadores de potássio

-Espironolactona

- Triantereno, Amilorida

Hipoaldosteronismo

Hipocortisolismo

Doenças tubulares renais

Ureterojejunostomia

\section{- Diagnóstico/Manifestações Clínicas}

O diagnóstico é feito, quando encontramos concentração sérica acima de $5 \mathrm{mEq} / \mathrm{l}$. Do ponto de vista clínico, a hiperpotassemia pode manifestar-se desde a ausência de qualquer sintoma até parada cardíaca. As células excitáveis são as mais sensíveis aos altos valores de potássio, entre elas as células miocárdicas e as neuromusculares, o que se traduz em fraqueza, arreflexia, paralisia muscular (inclusive respiratória), parestesias e alterações cardíacas, conforme delineado na Figura 1.

Do ponto de vista prático, cabe ainda ressaltar:

a) hipocalcemia, hiponatremia e acidose metabólica intensificam a hiperpotassemia;

b) acidose metabólica produz uma hiperpotassemia "menos tolerável e mais grave" do que a acidose respiratória;

c) a hiperpotassemia vista na insuficiência renal crônica é mais tolerada que a da insuficiência renal aguda, o que se deve à adaptação dos mecanismos de defesa extra-renais; 


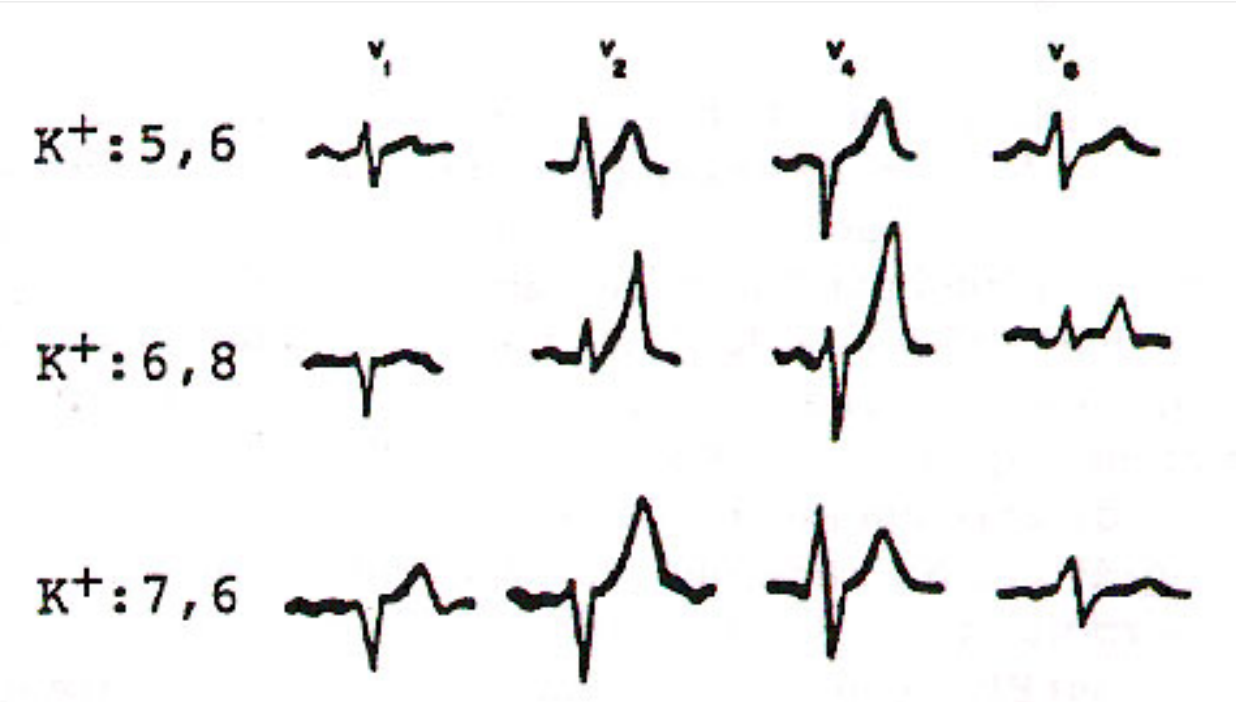

Figura 1 - Alterações eletrocardiográficas na hiperpotassemia.

d) deve ser sempre indagado, na história clínica, o uso de medicamentos, principalmente digitálicos;

e) quando a causa da hiperpotassemia for devida à carga de potássio aumentada (síndrome do esmagamento, hipercatabolismo ou hemólise maciça), associada a um déficit de excreção (insuficiência renal), poderá haver rápida elevação dos níveis de potássio, com riscos de parada cardiorrespiratória, nestas condições em que o tratamento dialítico deve ser considerado.

\section{Tratamento clínico}

Há três maneiras de se abordar a hiperpotassemia: antagonismo direto aos efeitos do potássio sobre a membrana, redistribuição do potássio do extra para o intracelular, e aumento da excreção do potássio.

1) Antagonismo direto sobre os efeitos do potássio na membrana celular: é o efeito observado durante a infusão endovenosa em bolus de gluconato de cálcio. Cloreto de cálcio também pode ser usado. O cálcio é a droga de escolha, quando existem alterações eletrocardiográficas ou na parada cardíaca por hiperpotassemia. A dose utilizada é de $10 \mathrm{ml}$ EV de gluconato de cálcio $10 \%$ em infusão lenta em 2 a 3 min, que pode ser repetida após $5 \mathrm{~min}$, se as alterações eletrocardiográficas persistirem. A ação é imediata (1-3 min) e a duração do efeito é de até $1 \mathrm{~h}$. Nos pacientes digitalizados, devese infundir o cálcio com extremo cuidado, e a dose descrita deve ser diluída em 100ml de SG 5\% e infundida em 20 a 30min, levando-se em conta que o cálcio pode induzir toxicidade digitálica. Deve-se ressaltar que o cálcio não diminui a concentração sérica de potássio, apenas antagoniza sua ação "tóxica" sobre o miocárdio.

2) Redistribuição do potássio: há três maneiras para se atingir tal objetivo: bicarbonato de sódio, solução polarizante (insulina + glicose) e agentes $\beta_{2}$-adrenérgicos.

a) Bicarbonato de sódio: quando há acidose, devemos calcular o déficit de bicarbonato através de seu volume de distribuição (Fórmula de Ash: Peso x BE x 0.3). É indicada a correção de metade do déficit, e a infusão deve ser feita via EV em 15 a 20 min. Quando não há acidose, doses menores de bicarbonato de sódio (cerca de $50 \mathrm{mEq}$ ) podem ser infundidas em aproximadamente 5 min, e podem ser repetidas após $30 \mathrm{~min}$. São contra-indicações ao uso do bicarbonato: edema pulmonar, devido à expansão de volume; e hipocalcemia, devido ao aumento da ligação do cálcio à albumina, quando ocorre aumento de $\mathrm{pH}, \mathrm{o}$ que pode precipitar convulsões e tetania. O início da ação ocorre em 5 a 10 min e a duração do efeito é de aproximadamente $2 \mathrm{~h}$. 
b) Solução polarizante: a infusão de insulina aumenta a captação do potássio pelas células musculares através de mecanismo descrito anteriormente. Para evitar hipoglicemia, deve-se usar 1 UI de insulina regular para 4-5g de glicose. Habitualmente, prepara-se solução com 100ml de glicose $50 \%+10$ UI de insulina regular, que deve ser administrada em infusão EV em 5-10 min. Pacientes com hiperglicemia intensa devem ser medicados apenas com insulina. O início da ação ocorre em $30 \mathrm{~min}$, com o pico em $60 \mathrm{~min}$ e o efeito se prolonga por 4 a $6 \mathrm{~h}$.

c) Agentes $\beta_{2}$-adrenérgicos: seu uso aumenta a captação celular de $\mathrm{K}^{+}$através de mecanismo descrito anteriormente. Podem ser usados por via inalatória (10 a 20mg de albuterol diluídos em $5 \mathrm{ml}$ de SF $0,9 \%)$, ou por infusão EV $(0,5 \mathrm{mg}$ de albuterol diluído em $100 \mathrm{ml}$ SG5\%). O pico de ação ocorre em 30 min, em infusão endovenosa, e em 90 min por via inalatória. Deve-se evitar o uso desdas drogas para o tratamento da hiperpotassemia devido a seu potencial arritmogênico.

3) Eliminação do potássio: há três maneiras para se atingir tal objetivo: resinas de troca iônica, diuréticos de alça, e procedimentos dialíticos.

a) Resinas de troca iônica: adsorvem $\mathrm{K}^{+}$no tubo digestivo, trocando-o por $\mathrm{Ca}^{++}$ou $\mathrm{Na}^{+}$. Em nosso meio, a resina mais usada é o poliestirenossulfonato de cálcio $\left(\right.$ Sorcal $^{\mathrm{R}}$ ) que troca $\mathrm{K}^{+}$por $\mathrm{Ca}^{++}$, sendo o primeiro eliminado nas fezes. Seu efeito se inicia após 1-2 h, com duração de até 6 h. É apresentada na forma de pó para uso oral, diluído em água. A prescrição habitual é de 15$30 \mathrm{~g}$ VO a cada 6 ou $8 \mathrm{~h}$. Pacientes que não possam usar a medicação por via oral podem ser tratados por enema de retenção. O efeito colateral mais freqüente é a constipação intestinal, que deve ser tratada com catárticos (Manitol ou Sorbitol).

b) Diuréticos de alça: o uso de diuréticos de alça (furosemida: 40 a $80 \mathrm{mg}$ EV ou bumetanida: 1 a $2 \mathrm{mg}$ EV) aumenta a excreção renal de potássio. Pacientes com insuficiência renal moderada a grave (clearance de creatinina entre 10$50 \mathrm{ml} / \mathrm{min}$ ), podem ser medicados com essas drogas, entretanto a resposta não é tão boa quanto em pacientes com função renal normal. Pacientes com insuficiência renal terminal não apre- sentam resposta satisfatória. Em casos de hiperpotassemia grave devem ser usados desde o início, apesar do efeito ser lento, pois nestes casos, pequenas perdas de $\mathrm{K}^{+}$podem provocar quedas consideráveis nos níveis plasmáticos. Por exemplo, para reduzir o potássio sérico de 7 para $6 \mathrm{mEq} / \mathrm{l}$, é necessário excretar muito menos $\mathrm{K}^{+}$ do que para reduzi-lo de 6 para $5 \mathrm{mEq} / \mathrm{l}$.

c) Mineralocorticóides: provocam aumento da secreção tubular de $\mathrm{K}^{+}$, e da reabsorção de $\mathrm{Na}^{+}$, o que limita seu uso. A droga mais usada é a fludrocortisona $\left(\right.$ Florinef $^{\mathrm{R}}$ ) na dose de $0,1 \mathrm{mg} / \mathrm{dia}$, podendo chegar a $0,2 \mathrm{mg} / \mathrm{dia}$ em casos excepcionais.

d) Diálise: é muito efetiva em retirar o potássio, principalmente a hemodiálise, e pode normalizar os níveis de $\mathrm{K}^{+}$em 15 a 30 min. Está indicada na insuficiência renal (aguda ou crônica). A principal desvantagem do tratamento dialítico é o tempo necessário para se preparar o material e para se conseguir o acesso (peritoneal ou através da punção venosa, para implante de cateter de duplo lúmen). Antes de preparar a diálise, deve-se utilizar as medidas terapêuticas apresentadas acima.

\section{3- Hipopotassemia}

Os termos hipocalemia ou hipopotassemia são utilizados quando a concentração do potássio no soro é inferior a 3,5 mEq/l, não distinguem o déficit total de potássio no organismo das alterações de distribuição do mesmo. Contudo, a hipopotassemia avaliada em conjunto com dados clínicos e laboratoriais oferece orientação quanto a etiologia, o prognóstico e a terapêutica não só do próprio distúrbio, como, também, de outros problemas que o paciente apresenta. Perdas de 200 a $400 \mathrm{mEq}$ são necessárias para promover a queda do $\mathrm{K}^{+}$sérico de 4,0 para 3,0 $\mathrm{mEq} / \mathrm{l}$, e perdas subseqüientes de 200 a $400 \mathrm{mEq}$ são necessárias para levar a potassemia a níveis abaixo de $2,0 \mathrm{mEq} / \mathrm{l}$.

A hipopotassemia ocorre em consequiência de: fatores que influenciam a distribuição transcelular do potássio; depleção do potássio corporal total; ou uma combinação desses fenômenos. A causa mais comum da distribuição transcelular é a alcalose, seja ela respiratória ou metabólica, embora ocorra, também, com a administração exógena de glicose, insulina ou betaagonistas. Os verdadeiros déficits de potássio resultam de perdas gastrointestinais ou renais, raramente de per- 
das pelo suor. Pode-se prever o desenvolvimento de hipopotassemia na presença de perdas através de secreções do trato gastrointestinal. As causas renais mais comuns incluem terapêutica com diuréticos ou estados de secreção excessiva de mineralocorticóide.

\section{Sinais sintomas}

Como o potássio é o cátion mais abundante no intracelular, é de se esperar que a hipopotassemia produza distúrbios em múltiplos órgãos e sistemas Os principais sintomas decorrem de aberrações na polarização das membranas que afetam a função dos tecidos neural e muscular. Os sinais e sintomas não aparecem habitualmente, até que a deficiência seja significativa.

\section{Cardíacos}

Alterações de condução cardíaca constituem as anormalidades mais importantes. A alteração do ECG, visualizada, é o achatamento das ondas "T" e desenvolvimento de ondas "U" proeminentes, que podem dar a impressão de um intervalo QT prolongado. Predispõem a batimentos ectópicos atriais e ventriculares e o aspecto mais crítico é o aumento da sensibilidade ao digital, levando a arritmias, potencialmente fatais, da intoxicação digitálica. A hipopotassemia reduz a eliminação da digoxina, aumentando seu nível sérico e aumentando a ligação da droga ao coração.

\section{Hemodinâmicos}

Foi constatado que a depleção de potássio aumenta a pressão arterial em voluntários humanos; por outro lado, a sobrecarga de potássio diminui a pressão arterial devido à natriurese.

\section{Neuromusculares}

Nos indivíduos com função cardiovascular normal, os sintomas de depleção de potássio não costumam ser evidentes, até que o déficit ultrapasse $5 \%$ das reservas corporais totais $(200 \mathrm{mEq})$, com níveis séricos de potássio inferiores a 3,0 mEq/l. As disfunções do trato gastrointestinal com hipopotassemia manifestam-se sob a forma de constipação ou íleo paralítico. Nos músculos estriados, pode-se notar desde leve fraqueza até a paralisia franca, com paralisia respiratória, ameaçando a vida do indivíduo, o que pode ocorrer, quando concentrações séricas de potássio são inferiores a 2,0 mEq/l. Ocorre, também, predisposição à rabdomiólise e à mioglobinúria, as quais podem levar à necrose tubular aguda.

\section{Renais}

A hipopotassemia grave pode resultar em declínio funcional do fluxo sanguíneo renal e da taxa de filtração glomerular, que costuma ser reversível com a reposição do potássio. Outra complicação grave da hipopotassemia é a mioglobinúria, que pode induzir à insuficiência renal aguda. $\mathrm{O}$ defeito mais comum é a incapacidade de concentrar a urina ao máximo, ocorrendo poliúria. Ocorre, também, uma produção aumentada de amônia, o que explica porque pacientes hepatopatas, com cirrose, evoluem para coma hepático. Hipopotassemia também potencializa insuficiência renal aguda nefrotóxica (aminoglicosídeos, anfotericina B).

\section{Endócrinas}

Quando há hipopotassemia grave, a liberação da insulina pelo pâncreas é inibida, o que provoca uma tolerância anormal aos carboidratos nos pacientes hipopotassêmicos. Isso complica o tratamento do paciente diabético e, em certas situações, estabelece-se um falso diagnóstico de diabetes mellitus.

\section{Diagnóstico diferencial}

Pode ser útil, no diagnóstico diferencial, o quadro clínico, parâmetros laboratoriais, como valores gasométricos, determinações urinárias do potássio e cloreto, e, em alguns casos, a avaliação do sistema renina-angiotensina-aldosterona, assim como a presença ou ausência de hipertensão arterial.

\section{Pseudo-hipopotassemia}

As amostras de sangue com alta contagem de leucócitos $\left(>10^{5} / \mathrm{ml}\right)$, conservadas à temperatura ambiente, sofrem uma redução na concentração de potássio, devido a sua captação pelos leucócitos, que pode ser evitada, se houver separação imediata do soro ou do plasma, ou armazenamento do sangue a $4^{\circ} \mathrm{C}$.

\section{Hipopotassemia secundária a redistribuição}

A questão que se impõe conhecer é se a alteração é na distribuição ou um verdadeiro déficit. As causas de redistribuição são as seguintes:

a) Alcalose: é a causa mais comum da redistribuição do íon. Está associada a grandes déficits, em torno de 200-500 mEq do íon, na alcalose metabólica, enquanto a alcalose respiratória induz pouco ou nenhum déficit.

b) Excesso de insulina: a elevação da insulina sérica estimula a captação do potássio pelas células musculares e hepáticas. 
c) Agonistas $\beta_{2}$-adrenérgicos: durante o uso desses agentes ou no estresse, em que ocorre liberação de catecolaminas, que é fenômeno agudo e transitório, pode ocorrer hipopotassemia, com duração de 60 a 90 min. Em pacientes susceptíveis, pode ocorrer predisposição a arritmias.

d) Paralisia periódica hipocalêmica: distúrbio raro com transmissão autossômica dominante. Caracterizase por ataques recorrentes de paralisia flácida em tronco e membros, com duração de 6 a 24 h. Os pacientes com tireotoxicose parecem ser propensos ao desenvolvimento dessa síndrome reversível.

e) Intoxicação por bário: a ingestão de sais de bário, solúveis em ácido, pode causar paralisia flácida hipocalêmica, por impedir o fluxo normal de potássio para fora das células,causando fraqueza muscular. Essa paralisia é caracterizada por vômitos, diarréia e precipitação de sais de bário (radiopaco) nos rins.

f) Intoxicação por tolueno: causada pela inalação de cola e tintas em aerossóis. A hipopotassemia ocorre pela acidose tubular renal distal e pela redistribuição inadequada.

\section{Depleção de Potássio}

a) Perdas extra-renais: as causas mais comuns consistem na perda pelo trato gastrointestinal inferior, tais como diarréia de grande volume, drenagem copiosa de uma fístula, presença de adenoma viloso e abuso crônico de laxativos. A ingestão inadequada de potássio, isolada, representa causa pouco habitual de hipopotassemia, mas pode ser encontrada na anorexia nervosa e no idoso com dieta restrita de chá e torradas. A excreção urinária de potássio, nessas duas situações, deve ser inferior a $20 \mathrm{mEq} /$ dia, mas a concentração urinária de potássio pode fornecer um valor falso devido à poliúria. Pode-se utilizar a fração de excreção de potássio, fornecendo valores abaixo de $6 \%$ ou ainda a relação $\mathrm{K}$ (mEq)/ Creatinina (g) menor do que 20, para uma avaliação rápida. Para uma boa avaliação, o paciente necessita estar euvolêmico e excretando mais de $100 \mathrm{mEq}$ de sódio por dia, pois a queda da taxa de filtração glomerular e o aumento da reabsorção proximal de sódio e água, em pacientes hipovolêmicos, reduzem a caliurese.

b) Perdas renais: excreção de mais de $20 \mathrm{mEq} /$ dia de potássio, acompanhada de hipopotassemia. A abordagem é feita, subdividindo os distúrbios em síndromes hipertensivas e normotensivas.

\section{1) Síndromes hipertensivas}

- Síndromes de hiperreninemia: hipertensão renovascular, hipertensão maligna ou acelerada, tumores produtores de renina (hemangiopericitomas pequenos, tumor de Wilms, adenocarninoma renal). Dados clínicos laboratoriais e angiográficos estabelecem o diagnóstico.

- Síndromes de hiporreninemia: essas síndromes ocorrem pela secreção autônoma de aldosterona (adenomas), ou na hiperplasia da supra-renal. As síndromes podem, também, manifestarse devido a outros mineralocorticóides exógenos, como o alcaçuz, que contém o ácido glicirrizínico, que sensibiliza os rins aos efeitos deles, ou por esteróides endógenos, como na Síndrome de Cushing, na produção ectópica de hormônio adrenocorticotrópico, e, ainda, na secreção de deoxicorticosterona ou de corticosterona, nas síndromes de hiperplasia supra-renal congênita. Outros distúrbios relacionados com a produção endógena de mineralocorticóides podem, também, levar a hiporreninemia (ex: Síndrome de Liddle, que é uma patologia conseqüente à expressão aumentada dos canais de sódio amiloridessensíveis).

\section{2)Distúrbios normotensivos}

- Síndromes com hipobicarbonatemia: a acidose tubular renal distal e proximal, a cetoacidose diabética, a terapêutica com acetazolamida, e a ureterossigmoidostomia são patologias nas quais ocorre perda renal do potássio, associada, também, com baixas concentrações séricas de bicarbonato. A acidose tubular renal proximal apresenta acidose hiperclorêmica, urina ácida e perda de outras substâncias, como ácido úrico, fosfato, glicose, aminoácidos, enquanto, na acidose tubular distal, há acidose hiperclorêmica, incapacidade de acidificar a urina e cálculos.

- Síndromes com hiperbicarbonatemia: essas síndromes são estudadas de acordo com a excreção urinária de cloreto. A hiperbicarbonatemia e a excreção urinária aumentada de cloreto (10mEq/dia) estão associados à exposição excessiva a diuréticos espoliadores de $\mathrm{K}^{+}$, síndrome de Bartter, síndrome de Gitelman e hipomagnesemia. A exposição a diuréticos leva à caliurese sem alcalose, contudo, a excreção urinária de cloreto é alta, apesar da contração de volume, que estimularia a conservação de cloreto de sódio. As síndromes de Bartter e de Gitelman 
são patologias raras, caracterizadas por normotensão, hiperaldosteronismo hiper-reninêmico, resistência a agentes pressores e alcalose hipocalêmica, que resultam de defeito no cotransportador $\mathrm{Na}^{+} / \mathrm{K}^{+} / 2 \mathrm{Cl}^{-}$, na alça de Henle e no cotransportador $\mathrm{Na}^{+} / \mathrm{Cl}^{-}$no túbulo distal, respectivamente. A hipomagnesemia causa perda renal de potássio e de cloreto, que resiste à terapêutica até haver reposição das reservas corporais de magnésio. Além disso, a hipomagnesemia leva à diminuição da secreção de $\mathrm{PTH}$, o que gera hipocalcemia. Por isso, a concomitância de hipocalcemia sugere a pesquisa dos níveis séricos de magnésio.

\section{Tratamento}

O tratamento é voltado para correção do déficit de potássio e da doença de base. Se a concentração sérica cair abaixo de $3,0 \mathrm{mEq} / \mathrm{l}$ ou se aparecerem os sintomas, a terapêutica é recomendada. Aos pacientes em uso de glicosídeos cardíacos ou pacientes idosos, sem cardiopatia manifesta, recomenda-se manter a normopotassemia. Em pacientes que fazem uso de diuréticos para tratamento de edema (ICC, síndrome nefrótica e hepatopatias) é aconselhável a suplementação oral, ou o uso de diuréticos poupadores de potássio (espironolactoma, amilorida ou triantereno).
As preparações orais de cloreto de potássio podem causar irritação gástrica e os comprimidos entéricos podem produzir ulcerações no intestino delgado.

A via de administração pode ser tanto oral quanto parenteral. Quando houver comprometimento da função gastrointestinal, nível sérico de $\mathrm{K}^{+}$abaixo de $3,0 \mathrm{mEq} / \mathrm{l}$, ou sinais e sintomas, a terapia parenteral deve ser preferida. A preparação mais usada é $\mathrm{KCl}$ $19,1 \%$, na qual, cada ml possui $2,5 \mathrm{mEq}$. A administração endovenosa deve ser preparada em uma solução de soro fisiológico $0,9 \%$, com concentração final de 40 a $60 \mathrm{mEq} / \mathrm{l}$ e infundida em $6 \mathrm{~h}$, se for usada veia periférica, pois concentrações maiores causam irritação e esclerose da veia. Soluções mais concentradas devem ser infundidas em veia central, e a velocidade de infusão não deve exceder $20 \mathrm{mEq} / \mathrm{h}$, com dose diária máxima de $200 \mathrm{mEq}$. Em casos extremos, com hipopotassemia grave e risco iminente de parada cardíaca, podem ser infundidos até $100 \mathrm{mEq} / \mathrm{h}$, com monitorização eletrocardiográfica. É descrita, também, infusão endovenosa, em 1 a 2 min de quantidades de $\mathrm{KCl}$, suficientes para elevar a potassemia até o nível desejado, em casos gravíssimos. Por exemplo, em paciente adulto de $70 \mathrm{Kg}$, com $\mathrm{K}^{+}=1,0 \mathrm{mEq} / 1$, levando-se em conta que possui volemia em torno de $5000 \mathrm{ml}$ e volume plasmático de $3000 \mathrm{ml}$, se o desejado é elevar a potassemia para 3,0 mEq/l, infunde-se $6,0 \mathrm{mEq}$ de $\mathrm{KCl}$ em 1 a 2 min, com monitorização eletrocardiográfica.

VIEIRA NETO OM \& MOYSÉS NETO M. Fluid and electrolyte disorders. Medicina, Ribeirão Preto 36: 325-337, apr./dec. 2003.

ABSTRACT - Sodium and potassium are the main extracellular and intracellular space electrolytes respectively. The disorders related to these electrolytes are frequent and may be caused by several clinical conditions. The physiopathology and severity of the changes determine the treatment to be instituted.

UNITERMS - Sodium. Potassium. Hyponatremia. Hypernatremia. Hypokalemia. Hyperkalemia.

\section{BIBLIOGRAFIA CONSULTADA}

1 - ADROGUÉ HJ \& MADIAS NE. Hypernatremia. New Engl J Med 342: 1493-1499, 2000.

2 - ADROGUÉ HJ \& MADIAS NE. Hyponatremia. New Engl J Med 342: 1581-1589, 2000.

3 - MAEASAKA JK. An expanded view of SIAHD, hyponatremia and hypouricemia. Clin Nephrol 46:79-83, 1996.

4 - MAEASAKA JK; GUPTA S \& FISHBANE S. Cerebral saltwasting syndrome: does it exist? Nephron 82: 100-109, 1999.
5 - HARRIGAN MR. Cerebral salt wasting syndrome. Critical care clinics 17:125-138, 2001.

6 - NARINS RG; HEIFTS M \& TANNEU RL. Paciente com hipocalemia e hipercalemia. In: SCHRIER RW. Manual de Nefrologia, diagnóstico e tratamento. $3^{\underline{a}}$ ed. Medsi, Rio de Janeiro, p. 51-75, 1993.

7 - BREZIS M; ROSEN S \& EPSTEIN FH. Acute renal failure. In: BRENNER BM \& RECTOR Jr FC. The kidney. 4ª ed. Philadelphia, W.B. Saunders, chap.24, p. 993-1061, 1991.

8 - HALPERIN ML \& KAMEL KS. Potassium. Lancet 352: 135-140, 1998. 